\title{
Policy Process for Children and AIDS in Cambodia: Drivers and Obstacles
}

\author{
Jerker Edström, Jenne Roberts and Andy Sumner, \\ with Choub Sok Chamreun
}

\begin{abstract}
1 Introduction and background
This study aims to analyse and address the question of how policy is made for children and HIV in Cambodia. First however, we look at the background of Cambodia, its HIV epidemic and vulnerable children. ${ }^{1}$ We then explain our methodology in the study, summarise findings on three areas of policy for children relating to HIV and conclude with some lessons.

Almost half of the Cambodian - predominantly Buddhist and rural - population (13.8 million people) are aged 18 years and under. Since the peace treaty was brokered in the early 1990s, the country has enjoyed increased economic growth (8.4 per cent per annum from 1994 to 2006) and relative stability, despite bouts of targeted political violence. Poverty persists, with 36 per cent of people living on less than US\$0.63 a day (NIPH and NIS 2006), while there are growing inequalities in wealth, with increased urbanisation, mobility and people marginalised in the process, many turning to informal peri-urban livelihoods strategies (World Bank 2007a). Involvement in economic activity starts early and rises sharply with age, contributing to delayed school entry and early school dropout. $A$ recent study found that an estimated 52 per cent of 7-14-year-olds and 16 per cent of children aged six were economically active (World Bank 2006).
\end{abstract}

Cambodia has had one of the highest HIV prevalence rates in Asia, but prevention efforts have been relatively successful and there has been a steady decrease in HIV prevalence from an estimated 2 per cent in 1998 to the current level of 0.9 per cent among people 15-49 years, as described in Figure 1.
Prevention efforts are targeting female sex workers, their clients and other sexual partners, men who have sex with men (MSM) and the small but growing numbers of injecting drug users (IDU), as well as broader groups (NAA 2007). The epidemic is primarily driven by heterosexual transmission and many men who have sex with men are married to and also have sex (and children) with - women. Approximately one-third of all new infections are among children (with considerable numbers through sexual transmission ${ }^{2}$ ) and half are among females (NCHADS 2007a).

An estimated 8.8 per cent of Cambodians aged 0-17 years are orphans ${ }^{3}$ and a further 6.1 per cent have a chronically ill parent (op cit.). These two groups (ca. 15 per cent of children) make up the predominant proportion of the category referred to as 'orphans and vulnerable children' (OVC), which (being an orphan or ill) is not necessarily related to HIV per se. To differentiate and describe the more HIV-relayed category of children infected or otherwise directly affected by HIV and AIDS, we use the concept of children affected by HIV or AIDS (CAA). However, we have no reliable estimates of the number of CAA, though we can be fairly certain that they represent a minority of all OVC. The number of children aged 0-14 years living with HIV/AIDS in Cambodia and the number of new HIV infections occurring each year among children in this age group were projected to be 2,790 children in 2007 (NCHADS 2007a). By September 2007, there were 22 sites providing care and treatment to 2,960 children including 1,739 receiving antiretroviral treatment (ART) (NCHADS 2007b). 
Figure 1 Estimated prevalence of HIV infection among persons aged 15-49 in urban and rural locations in Cambodia, 1995-2006

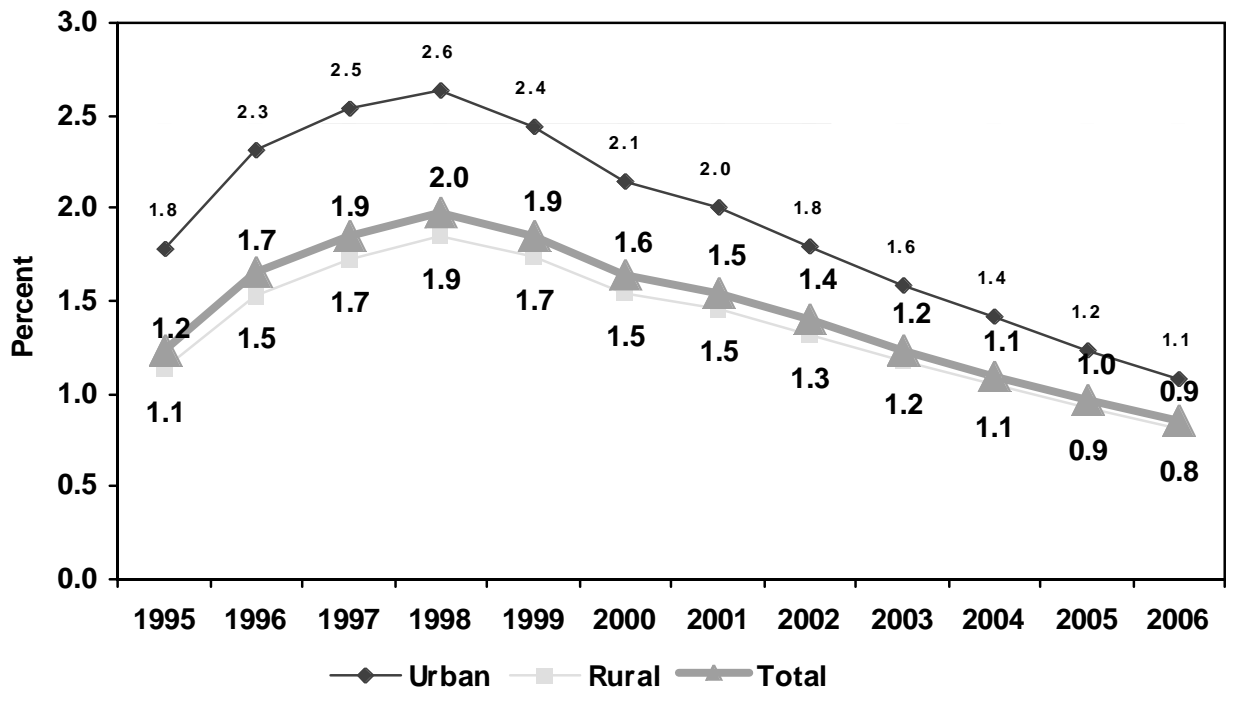

National Center for HIV/AIDS, Dermatology and STD Surveillance Unit (2007).

National expenditure on health and education has increased, but the government is constrained by relatively low levels of capacity and resources (CDRI 2007), while the country continues to receive substantial international aid. Expenditure of national resources on HIV, education or support to OVC is limited, but includes support for basic wages for staff, infrastructure, school buildings and at least one orphanage in each of the 24 provinces (World Bank 2007b).

The National AIDS Programme of the Ministry of Health was reorganised in the late 1990s into the National Centre for HIV/AIDS, Dermatology and STIs (NCHADS), now the focal point of the health sector response to the epidemic. This was followed in 1999 by the establishment of the National AIDS Authority (NAA), with a mandate to ensure a multi-sectoral response. The Royal Government of Cambodia (RGC) ratified the United Nations Convention on the Rights of the Child in 1992 without reservations and children's rights were incorporated into the Constitution of Cambodia in 1993. In 2007, the government made a commitment to universal access to HIV prevention, treatment and impact mitigation by 2010 and the response to HIV/AIDS is outlined in the recently revised National Strategic Plan for a Comprehensive and Multi-sectoral Response to HIV/AIDS 2006-2010, known as NSP II (NAA 2007).

This study attempts to describe and assess the process, developments and effects of three sets of policies, as well as to speculate on the major drivers of change in each case in order to compare and to draw out key lessons, namely:

- The Policy for Alternative Care for Children

- The Impact Mitigation chapter of the second National AIDS Strategy (NSP II), which had led to a draft National Plan of Action for OVC at the time of the fieldwork

- The policies under the Continuum of Care, related to paediatric ART.

\section{Conceptual approach and methodology}

Policy and policy processes are notoriously difficult to define. Cunningham (1963) famously described policy as 'an elephant - you know it when you see it'. Policy processes involve different stages and spaces for influence, as well as levels that interact during the processes of formation and implementation. There is a bewildering array of theories for the analysis of the 
policymaking processes with some major differences (Buse et al. 2005, Court and Cotterrell 2004; KNOTS 2006; Gaventa 2006; Sutcliffe and Court 2005; Sutton 1999; Sabatier and Jenkins-Smith 1993). However, there are (fortunately) also some commonalities in analytical frameworks. These broadly speaking centre on power relations around three interlocking (or overlapping) domains, which are:

- Evidence and discourses underlying the policy narrative, i.e. values of the policy narrative or its construction and the ideas that trigger change

- Policy actors and their networks, their political interests and capabilities - or, the coalitions of change

- The institutions and context - or, 'system imperatives' and how the socioeconomic, political and cultural environment shapes policy processes and the 'rules of the game' and windows of opportunity for policy dialogue and influence.

Assumptions underlying this include: that 'evidence' used in policy processes is inherently contestable; that there is an unclear line between those who 'make' policy and those who 'influence' policy; and that policy processes may be non-linear and highly iterative in reality. We use the above as a definitional framing of policy processes to ask 'what factors actually determine policy change?'

The methods used were: literature review; semistructured key informant interviews with over 20 stakeholders; and a consultation meeting on preliminary analysis and findings, where 18 stakeholders fed back and proposed recommendations. Interviewees were selected from the three categories of:

(a) government, (b) international development agencies, and (c) non-governmental, community and faith-based organisations (including a small group of children benefiting from certain non-governmental organisation (NGO) services), based on their relevance to each of the three sets of policies.

\section{Findings}

Key findings and analysis are presented below, in separate subsections for each policy area.

\subsection{The Policy on the Alternative Care for Children}

The Policy on Alternative Care for Children was authorised by the Prime Minister on 11 April 2006 following a major regional meeting, a Call to Action for Children and HIV/AIDS, which was held in Hanoi in
March 2006. The Ministry of Social Affairs, Veterans and Youth Rehabilitation (MoSVY) is the authority responsible for issuing the policy and its implementation. Prior to developing this policy, a Cambodian delegation was sponsored by UNICEF to attend the second international conference on Children and Residential Care held in Stockholm in May 2003. Delegates heard evidence that institutional care has negative consequences for both individual children and for society at large which could be prevented.

The policy defines alternative care as 'care for orphaned and other vulnerable children who are not under the care of their biological parents'. The issue of alternative care is framed as one primarily related to accommodation. The policy outlines a hierarchy of preferences for placement options and mandates minimum standards for each type of alternative care. The evidence for this hierarchy is drawn from international 'best practice' and there is limited research or lessons from Cambodia guiding this. While the policy states that each child's unique situation should be considered when finding alternative care, many children are housed by the $\mathrm{NGO}$ they first come into contact with, and their needs are met according to the values and type of service that organisation provides. Some informants believe that the impetus for the policy came from child rights activists and that there was a marked lack of interest from government, so the policy had to be loose enough to be palatable to government and get agreement from everyone.

Following the Stockholm conference, the government established - and formalised by Government Prakas (decree) - the Alternative Care Advisory Committee and four working groups. The advisory group meets on an ad hoc basis usually in response to a request from one of the working groups (which are more active). The latter have work plans, prepare draft documents and call meetings to present these to the advisory committee. Of the four groups, one working group has completed its mandate, and the Minimum Standards for Residential Care have been adopted. All the community-based care standards for kinship-based care, foster care, pagoda-based care and group homes have been forwarded to the advisory committee. The standards have been guided by the practices of some local service providers, consideration of international best practice guidelines and evidence where it exists, although there has been limited consultation and 
input. This was variously explained as due to the absence of a database that identifies all alternative care providers (who are now all required to register with MoSVY), limited networks and opportunities to link, or resources required for consultation, along with a perceived unwillingness to open the discussion to a broad range of stakeholders.

Policy leadership is provided by the MoSVY Child Welfare Department, supported financially and technically by UNICEF, with input from the Alternative Care Advisory Committee, which advises the Secretary of State for MoSVY (who chairs the committee). The advisory committee includes representatives from UNICEF, the International Organisation for Migration $(\mathrm{IOM})$ and a small number of NGOs providing a range of types of care. In an overwhelmingly Buddhist country, faith-based organisations (Christian and Buddhist) are involved in providing alternative care, but the Buddhist groups are not represented on the advisory committee. Furthermore, while more than half of all orphanages are run by one Christian proselytising group, this organisation does not participate in consultations, did not agree to be interviewed and has a blanket 'no adoptions' policy for children in their orphanages. The HIV sector interests are also not represented in the working groups, and this is thought to have contributed to the lack of guidelines on HIV testing and treatment of children in alternative care. Many organisations working with children who have been subject to sexual exploitation also provide residential care, but they were not significantly involved in developing the standards. An NGO-led Child Welfare Group, which acts as a bimonthly networking forum with support from the Cambodian Co-ordination Committee (CCC), was not involved in the policy development process. However, this forum and the National OVC Task Force, provide avenues for dissemination, policy debate or developing strategies to monitor implementation.

The process was relatively 'closed' compared with the process of developing other policies to support children. $A$ limited range of stakeholders were invited to participate. Key stakeholders (such as organisations that have been developing models of communitybased care) were not invited and MoSVY is still widely regarded as having limited capacity or transparency. For example, inter-country adoption processes have raised repeated allegations of corruption, not helped by legislation stating that adoptive parents must pay a 'donation' to MoSVY.
There is a perception that some NGOs and government orphanages are involved with intercountry adoption brokers and services with questionable practices. UNICEF is working with MoSVY on a revised draft of the Adoptions Law, restricting the provisions for adoptions to noncitizens, but no public consultations on the draft have taken place and it has not been reviewed by the Alternative Care Advisory Committee.

The inclusion of alternative care as a key area for action in the National Plan of Action for Orphans and Vulnerable Children (discussed below) necessitated the establishment of a time-limited Alternative Care Working Group under the National OVC Task Force. This new group included a broader range of community-based care providers than MoSVY had previously developed links with. As they became aware that minimum standards for community-based care were being developed, the NGOs involved in developing the National Plan of Action advocated successfully for MoSVY to include them in the process, although the latter is reportedly reluctant to let new stakeholders join the Alternative Care Advisory Committee.

\subsection{Policy on impact mitigation under the second multi-sectoral National Strategic Plan on HIV/AIDS (NSP II)}

Impact mitigation policies to support children affected by HIV and AIDS are derived from Strategy 3 of the second National Strategic Plan for a Comprehensive Multi-sectoral Response to HIV/AIDS, 2006-2010, or NSP II. This arena is not one 'policy' as such, but rather an evolving process under the umbrella of the national response to HIV/AIDS.

Following a UNAIDS and UNICEF Global Campaign in 2005, a Call to Action for Children and HIV/AIDS meeting was held in Hanoi in March 2006, as mentioned above, and it is widely agreed that action to develop policies responding to children happened as a direct result of this 'Hanoi Call to Action'. A National Orphans and Vulnerable Children's Task Force was established on 10 July 2006. The Task Force immediately commissioned a situation and response analysis (MoSVY and NAA 2008a) to inform the development of a National Plan of Action for OVC (MoSVY and NAA 2008b), which was developed, 'costed', and prioritised for 2008-9. The process for developing the National Plan of Action began in early 2007 and was described as 
labour intensive, as well as only likely to be successful when accompanied by international donor support. The National Plan of Action was approved immediately prior to a follow-up Regional Consultation on Children and AIDS, in Bangkok in March-April 2008, and launched a month before the national elections on 20 June 2008. While national politics likely influenced this timing, a broader regional process, where national representatives share and compare with peers in the region - and the concomitant influence of global discourse and resources - played a major part (Edström and Khan, forthcoming).

Overall, the discourse in this area has been one imported from the evolving international policy discourse on children and AIDS and there was broad consensus that dialogue only progressed when the key government representatives had heard an issue discussed in an international forum. The HIV policy dialogue under this NSP II process involved children's services representatives and the term 'OVC' was introduced into government HIV plans for the first time. This coincided with the Universal Access campaign orchestrated internationally by UNAIDS, which recognised that impact mitigation for children affected by HIV/AIDS was lagging behind progress in other areas. While the National Plan of Action for OVC defines factors contributing to vulnerability, varying understandings of terms like OVC and CAA persist and tensions exist between those who believe efforts should focus on CAA versus those wanting to focus on the broader group of OVC - or even 'all vulnerable children'. For example, a senior representative of the National AIDS Authority (NAA) maintained that HIV policies target only children affected by HIV/AIDS, while the National OVC Task Force has agreed to adopt a broader approach that takes into account the needs of all OVC. This lack of consensus on definitions and purpose is reflected at the international and regional levels and it affects efforts to estimate the size of the population, coverage of services and to track decision-making

In terms of key actors, leadership comes formally from the NAA, but is delegated to MoSVY. In practice, the sector recognises leadership by the agencies committed to working to take forward policies and plans to support children affected by HIV and AIDS, such as Save the Children, UNICEF, Friends/Mith Samlanh, the Khmer HIV/AIDS NGO Alliance (KHANA), Child Fund, CARE and Family
Health International (FHI). The government response to HIV overall is undisputedly led by the Director of NCHADS, and there is a desire to see this same level of leadership for the response to children from MoSVY. Several participants in the Hanoi meeting stated that NCHADS represented the voice of the government, and that encouragement was extended to MoSVY to assume the leadership role. Once the commitment was made to scale-up impact mitigation efforts, it was difficult for MoSVY to maintain the disinterested position it had taken in relation to the pre-existing OVC Task Force, which had been established in 2004 under a project funded by USAID through the Policy Project.

The latter had led a Policy Dialogue workshop held in 2004 (Policy Project 2004), a research study into the social and economic costs of HIV-affected families with children and adolescents (Alkenbrack et al. 2004), and a legal and policy audit to document the policy response and gaps for vulnerable children, including those affected by HIV (Elliott 2004). KHANA and several international NGOs have formed strong partnerships with local groups to claim space in the policy process. They were joined in 2007 by key development partners including the UK's Department for International Development (DFID), UNICEF, the World Food Programme and UNAIDS in developing the National Plan of Action for OVC. Representation of the views and interests of small local NGOs comes primarily from the national and international umbrella NGOs or agencies through which they receive funds. Over 300 local NGOs contributed input during a series of working group meetings and national workshops. The high level of engagement in the process has resulted in strong ownership of the National Plan of Action. Notably, however, children have no networks or forums that guarantee them input into the process.

Although MoSVY has officially taken leadership in this process, there are still key civil society actors that see MoSVY as harbouring corrupt government staff and UNICEF (MoSVY's development partner) as failing to tackle this head on. There was a pronounced sense that MoSVY has not yet taken on true leadership. One informant described MoSVY as 'sitting in the driver seat, but they have not yet gripped the steering wheel'. Many are hoping to see MoSVY take on sufficient leadership to unite the many organisations involved and some see the availability of donor resources and incentives as a key to progress in this. 
3.3 Policies for paediatric HIV care and treatment for children living with HIV under the Cambodian Continuum of Care ( $\mathrm{CoC}$ ) and 'linked response'

One key policy change has been the provision of free ART for children, nominally since 2005 . While some international NGOs had started providing treatment to children earlier, by the end of 2007, paediatric HIV care was scaled-up to 22 sites, and 2,372 children had received ART (Chhorvann 2007). The NCHADS Strategic Plan for HIV/AIDS and STI prevention and care in the health sector in Cambodia states an intention to integrate paediatric AIDS care into paediatric care services, effectively mainstreaming it out of specialised (adult) treatment services and under the responsibility of hospital-based paediatric teams.

The policy discourse is framed in the standard operating procedures (SOP) for the continuum of care and informed by the universal access targets for 2010 of 95 per cent coverage. The SOP is the point of reference and there are baseline indicators and targets. There is no separate policy document but access to treatment for children is now 'the policy'. While the justification is rights-based, the overall 'evidence' that the policy is needed was described by various stakeholders as information from homebased care (HBC) teams about cases of HIV-positive children, which provided the grounds for setting up the policy and guidelines. Health staff mentioned that justifying the policy is still not always easy, as some feel that 'incurability' means that treatment is a waste of money. The Ministry of Health puts forward an argument related to the rights of the child. Further evidence on appropriate case management, etc. is drawn from a combination of international World Health Organization (WHO) guidelines and local biomedical research carried out by the NCHADS Social Health Clinic, the National Paediatric Hospital, the Pasteur Institute, and Médecins Sans Frontières (MSF). It is described by several key informants as a robust combination of locally generated evidence and international best practice. There is now a two-year research agenda in place, led by the National Institute of Public Health (NIPH), which includes biomedical research on HIV and other diseases, such as tuberculosis. While the discourse has been a rights-based one, framed in political and bureaucratic commitments to universal access, it responded quickly to the concrete evidence of real need from the field, the availability of funds, as well as local examples of ability to provide treatment in resource-poor settings.
The international NGOs, Mary Knoll and MSF were the initial key actors leading the way on ART for children, and their experience convinced the Ministry of Health and donors that treatment was possible and affordable. However, the speed with which this process developed also has to be understood against the backdrop of broader NGO-government collaboration going back many years. $A$ key factor in care and treatment was an unusual engagement between the local civil society platform KHANA and NCHADS, in which the two collaborated directly in scaling-up a model of home and community-based care. Other key actors subsequently got involved, such as the international NGOs CARE and FHI. The paediatric ART received a particular boost from the Clinton Foundation, which stepped in to assist in negotiating affordable drugs and now provides both funding and technical support to NCHADS. A range of other international actors, such as WHO, UNAIDS, UNICEF and the Global Fund, were also described as providing vision, resources and expertise. While Mary Knoll and MSF pioneered the path in providing treatment to children on a limited scale, the government engaged and worked with a range of stakeholders in scaling-up care and treatment overall, within the context of a pre-existing productive culture of collaboration between NGOs and government. This engagement between NCHADS and credible implementing partners has created a strong sense of shared ownership and cooperation.

A defining feature of the process for developing policies and operating procedures in paediatric ART has been their evolution as iterative processes, undertaken by task-oriented working groups with members selected and invited by NCHADS, and the purposive integration of paediatric ART into the broader paediatric health services (as for preventing mother-to-child transmission of HIV (PMTCT) services into Maternal and Child Health). The actual SOPs were developed with support from WHO, FHI, UNICEF, Centers for Disease Control and Prevention (CDC) in the USA, and KHANA (on community and homebased care in the latter case). The national guidelines were first developed in 2004 and updated in 2007. Expert groups developed different areas, with experts writing on specific issues, after which groups got together and put the guidelines together. It took approximately one year to develop the draft. Following that, there was extensive consultation amongst group members through email as well as several meetings on specific areas, before the SOPs were finalised. There is 
Table 1 Selected significant features of each policy process, by three 'domains'

\begin{tabular}{|c|c|c|c|}
\hline & Discourse and evidence & Actors and networks & Institutions and context \\
\hline $\begin{array}{l}\text { Alternative } \\
\text { care }\end{array}$ & $\begin{array}{l}\text { Driven by global } \\
\text { discourses. Formulaic } \\
\text { and limited local } \\
\text { evidence or } \\
\text { adaptation. }\end{array}$ & $\begin{array}{l}\text { Limited to some key } \\
\text { institutions, leaving out } \\
\text { major stakeholders. } \\
\text { Limited ownership. }\end{array}$ & $\begin{array}{l}\text { Impeded by formal domestic } \\
\text { institutions (lack of participatory } \\
\text { processes). }\end{array}$ \\
\hline $\begin{array}{l}\text { Impact } \\
\text { mitigation }\end{array}$ & $\begin{array}{l}\text { Gaps in evidence and } \\
\text { disagreements on the } \\
\text { framing and discourse. }\end{array}$ & $\begin{array}{l}\text { Actors engaging from } \\
\text { diverse sectors. Leadership } \\
\text { increasing. }\end{array}$ & $\begin{array}{l}\text { More participatory structures } \\
\text { spurred by new opportunities. }\end{array}$ \\
\hline $\begin{array}{l}\text { Paediatric } \\
\text { ART }\end{array}$ & $\begin{array}{l}\text { Health sector focus, and } \\
\text { low profile as a (non-)policy. } \\
\text { Combines global and local } \\
\text { research evidence. }\end{array}$ & $\begin{array}{l}\text { Engaging leadership as a } \\
\text { crucial driver. Relatively little } \\
\text { 'contestation' and strong } \\
\text { ownership. }\end{array}$ & $\begin{array}{l}\text { Strong management. Invited } \\
\text { consultation with key actors. } \\
\text { Iterative process. Little front-line } \\
\text { influence }\end{array}$ \\
\hline Lessons & $\begin{array}{l}\text { - 'Children and AIDS' } \\
\text { discourse is imported from } \\
\text { global debates and is } \\
\text { contested. } \\
\text { - Local evidence needed and } \\
\text { increasing; follows but does } \\
\text { not lead policy. } \\
\text { - Conflicting discourse and } \\
\text { framings in global policy is a } \\
\text { constraint. }\end{array}$ & $\begin{array}{l}\text { - Leadership matters and } \\
\text { works well when leaders } \\
\text { invite relevant partners. } \\
\text { - Broad engagement is } \\
\text { needed for credibility and } \\
\text { ownership. } \\
\text { - Leaders need global } \\
\text { supporters, who also import } \\
\text { their own conflicts. }\end{array}$ & $\begin{array}{l}\text { - Working groups, etc. create } \\
\text { iterative spaces for finding } \\
\text { solutions and shared ownership. } \\
\text { - Community voices can be } \\
\text { supported, with intermediary } \\
\text { support. } \\
\text { - Global incentives move and } \\
\text { perceived corruption hinders. }\end{array}$ \\
\hline
\end{tabular}

regular training on how to use the guidelines for medical staff, including from the provinces and from some NGOs. The policy was revised in 2007 on the basis of lessons being learned from Thailand, while this revision involved a similar but shorter process. Now there is a collaborative paediatric study involving Thailand and Cambodia, led by the NIPH and the National Paediatric Hospital in Cambodia.

The process evolved rather 'organically', initially raising different concerns over due process, opportunities and resources, but became 'institutionalised' over time. One informant recalled how the NCHADS Director was initially reluctant, due to the concomitant obligation to treat children for life. Confidence around sustainability is growing and the informant said, 'when the Clinton Foundation finishes funding treatment for children, we will find someone else'. The government has engaged with other actors in spaces claimed by civil society and international agencies, while - in the process - 'taking over' the leadership. In doing so, it has also opened and managed new spaces for engagement on a basis of 'credible' cross-sector stakeholder involvement. This includes active efforts to bring in and support the participation of adults living with HIV or AIDS, down to provincial and district levels.

\section{Concluding discussion}

What do the case studies tell us? While each case study contains intriguing material with many interpretations and background factors, not addressed in detail here due to lack of space, it is instructive to draw out some broad comparisons, with reference to the framework adopted.

In summary, in the case of alternative care, policy change was driven by global discourses and impeded by formal domestic institutions (via a lack of participatory institutions or processes). For the process of developing a national OVC plan under the National AIDS Strategic Plan (NSP II), policy change was largely driven by actors and institutions (via more participatory structures) but impeded by gaps in evidence and disagreements on the framing and discourse. For operational policies to support 
paediatric ART for HIV-positive children, the leadership, strong management and consultation of key actors and networks were crucial drivers of success and ownership, while its specialised health sector focus, low profile as a (non-)policy and its strategically invited consultation (although including groups having claimed the policy space) has allowed it rapid progress with relatively little 'contestation'.

Table 1 highlights some major features of each policy process, by the three domains of the framework, for comparison, and suggests some key lessons.

If we focus on the role of discourse and evidence in the policy process, it varies significantly by policy. Political ammunition for policies to gain traction needs a locally relevant evidence base that engages both local leaders and development partners, although local research seems to follow rather than lead policy changes initiated by international discourse and resources. While much other child welfare action in Cambodia predates 2005, most of the 'children and AIDS' discourse is imported from global policy arenas. The analysis revealed very different understandings of terms like orphans and vulnerable children (OVC) and children affected by HIV/AIDS (CAA), with concomitant tensions between actors in the NSP I| process. The policy for alternative care is not HIV-specific, while policies in support of paediatric treatment of HIV-positive children are highly specific, but integrated into the emerging broader paediatric health services. The cross-sectoral nature of the issue of children has provided particular challenges for establishing clear discourses and strong evidence in support of policies, which remains a fundamental obstacle at all levels up to global and regional policy debates. Clarifying these discourses and frameworks remains an important priority.

The types of actors and networks involved influence the shape that the process and policies take. Processes that are 'more closed' seem to produce policies that are less reality-based, less understood or accepted. Leadership clearly matters and seems to work particularly well where leaders invite relevant

\section{Notes}

1 We use the UN Convention of the Rights of the Child definition of a child, as any person under the age of 18 , unless otherwise specifically stated.

2 Although limited hard evidence exists, there are concerns that a number of infections may occur partners and hand over some real authority. Such leadership also seems to have been strengthened by, and attracted, international support. International actors can provide impetus and resources on specific issues, but also import their own conflicts and priorities to the national arena. It is difficult to overstate the influence of these actors in the Cambodian context. Community voices and HIVpositive people can be supported to engage with support from intermediary civil society organisations, which appears to work better at provincial and local levels than nationally.

In terms of institutions and interests involved, working groups, etc. can provide real opportunities for creating iterative spaces for elaborating and negotiating solutions, as well as building shared ownership, across stakeholders and interest groups over time. These groups involve complex power relations, but how this power is exercised also influences outcomes. Transparency and perceived good governance is important to the engagement of civil society and community groups, and the opposite hinders both the engagement of relevant groups and the ability of government actors to credibly take on a proactive leadership stance. The changing role of MoSVY in the process for development of the national plan for OVC, suggests that such positions can change, but that demonstrating change will be needed to overcome remaining mistrust.

Public participation, through civil society, has been essential to success in policymaking and implementation. It is notable, however, that meaningful child participation in these processes has been very limited and one might expect stronger prospects for developing such influence and participation if processes are decentralised to local levels, while supported by a broader national process and networks. The single most productive and important priority may well be for government, child rights and HIV NGOs to build on good examples and develop stronger processes, supporting children including adolescents - and civil society participation in policy formation, implementation and monitoring.

as a result of unsafe injections in healthcare settings, which cannot be discounted as an additional factor.

3 An orphan is defined as a child under 18 with at least one parent having died. 


\section{References}

Alkenbrack. S.; Ty, C. and Forsythe, S. (2004) The Social and Economic Impact of HIV/AIDS on Families with Adolescents and Children in Cambodia, The Policy Project, USAID

Buse, K.; Mays, N. and Walt, G. (2005) Making Health Policy, Maidenhead: Open University Press

CDRI (2007) Moving Out of Poverty? Changing Trends in Community Well-being and Household Mobility in Nine Cambodian Villages, Phnom Pheng: Cambodia Development Resource Institute (CDRI)

Chhorvann, C. (2007) 'Current Situation of HIV/AIDS Epidemic in Cambodia', consultative meeting on 'Situation and Response Analysis of HIV and AIDS in Cambodia', Phnom Penh, 27-28 November

Court, J. and Cotterrell, L. (2004) What Political and Institutional Context Issues Matter for Bridging Research and Policy? A Literature Review and Discussion of Data Collection Approaches, ODI Working Paper 269, London: Overseas Development Institute

Cunningham, C. (1963) 'Policy and Practice', Public Administration 41: 229-37

Edström, J. and Khan, N. (forthcoming) Protection and Care for Children Faced with HIV and AIDS in East Asia and the Pacific: Issues, Responses and Priorities in the Region, Insitute of Development Studies report to UNICEF/EAPRO, draft report submitted 2008

Elliott, C. (2004) OVC Policy and Legal Audit, Save the Children, Australia and the Policy Project, Cambodia

Gaventa, J. (2006) 'Finding the Spaces for Change: $A$ Power Analysis', IDS Bulletin 37.6: 23-33

KNOTS (2006) Understanding Policy Processes: A Review of IDS Research on the Environment, paper for the Knowledge, Technology and Society Team, Brighton: Institute of Development Studies (IDS)

MoSVY and NAA (2008a) Orphans, Children Affected by HIV and Other Vulnerable Children in Cambodia: A Situation and Response Assessment, 2007, Phnom Pehn: National Multi-sectoral Orphans and Vulnerable Children Task Force, Ministry of Social Affairs, Veterans and Youth and National AIDS Authority

MoSVY and NAA (2008b) Making a Significant and Lasting Difference: The National Plan of Action for Orphans, Children Affected by HIV and Other Vulnerable Children in Cambodia, 2008-1010, Working Document, March, Phnom Pehn:
Ministry of Social Affairs, Veterans and Youth and National AIDS Authority, www.unicef.org/eapro/ Cambodia-_National_Plan_of_Action_OVC.pdf (accessed 1 October 2008)

NAA (2007) National Strategic Plan for a Comprehensive and Multisectoral Response to HIV/AIDS 2006-2010, (Revised December 2007), Phnom Pehn: National AIDS Authority, Royal Government of Cambodia

NAA (2007) UNGASS Country Progress Report, Cambodia, Reporting Period: January 2006-December 2007, National AIDS Authority NCHADS (2007a) HIV Estimates and Projections for Cambodia 2006-2012, report of a Consensus Workshop, Phnom Penh, 25-29 June, National Center for HIV/AIDS, Dermatology and STD Surveillance Unit, Ministry of Health

NCHADS (2007b) Third Quarterly Comprehensive Report, HIV/AIDS and STI Prevention and Care Programme, Phnom Penh: Ministry of Health

NIPH and NIS (2006) Cambodia Demographic and Health Survey 2005, Phnom Penh, Cambodia and Calverton, Maryland, USA: National Institute of Public Health, Cambodia; National Institute of Statistics Cambodia

Policy Project (2004) Orphans and Vulnerable Children Policy Dialogue, report of a workshop held with the Ministry of Social Affairs, Veterans and Youth Rehabilitation, and CARE, 23-24 August, Phnom Penh

Sabatier, P. and Jenkins-Smith, H. (1993) Policy Change and Learning, Boulder: Westview Press

Sutcliffe S. and Court, J. (2005) A Toolkit for Progressive Policymakers in Developing Countries, London: Overseas Development Institute

Sutton, R. (1999) The Policy Process: An Overview, London: Overseas Development Institute

World Bank (2007a) Sharing Growth: Equity and Development in Cambodia, Report 39809-KH, Phnom Penh: World Bank

World Bank (2007b) East Asia and Pacific UpdateWill Resilience Overcome Risk? World Bank half yearly update, November, Phnom Penh: World Bank

World Bank (2006) Children's Work in Cambodia: A Challenge for Growth and Poverty, Understanding Children's Work (UCW) Report, Phnom Penh: World Bank 